\title{
Interrogating the Grammars of Institutions and Injustice
}

\author{
Deborah Bradley, Guest Editor
}

This editorial introduction to ACT 16 (3) explores institutions as sites of paradox whose mission statements (or constitutions in the case of government) suggest concerns for diversity and inclusion but whose "grammars" (Bonilla-Silva 2011) frame thought and action in ways that may prevent the very work towards equity that the statements promote. The grammars of institutional injustice serve to frame the way we (as actors within institutional settings) view social phenomena, as well as the way we experience these phenomena, thus influencing the way we talk about, frame, and strive to resolve matters of injustice.

Keywords: institutional injustice, social justice, racial grammar, systemic racism

You can know a thing to death and be for all purposes completely ignorant of it. (Marilynne Robinson, Gilead)

$\mathrm{I}$ t was one of the most difficult periods of decision making I have experienced in my life-wrestling with a decision about whether to stay at the University of Wisconsin-Madison, or to return to Toronto, where other different-butrelated opportunities had presented themselves like stars twinkling in a sky that I could touch and feel. Leaving meant walking away from a job for which I had spent years preparing, for which I felt qualified, and in which I felt a growing sense of accomplishment; returning to Toronto meant returning home-to my life partner, my adult son, to the friends I have known for so long, to my adopted country. Something about my life within the institution caused me a discomfort that I had found difficult to articulate or to reconcile with my teaching and research goals. It wasn't necessarily the bureaucratic nature of institutions-I had spent a great many years of my working life in corporations and other bureaucratic situations prior to entering academe, so I knew what to expect in that

(C) Deborah Bradley 2017. The content of this article is the sole responsibility of the author. The ACT Journal and the Mayday Group are not liable for any legal actions that may arise involving the article's content, including, but not limited to, copyright infringement. 
regard. There was something else going on that I just couldn't put my finger upon at the time.

I consulted with friends and a few select colleagues as I wrestled with my decision. One colleague in particular shared a pearl of wisdom that helped me begin to grapple with the lack of congruence that I sensed between my personal sense of purpose and the purpose that I perceived from the institution. I will forever recall her words: "Deb, you can love the institution, but the institution is never going to love you back." As I processed those words in the days that followed, I began to bring my discomfort into focus, to realize that the institution, with increasing intensity, seemed to perversely impede the accomplishment of the very goals for which I had been hired-to teach and conduct research related to social justice, specifically antiracism, in music education-even as I did the work for which I had been hired. A few weeks later I announced my retirement from UW, and began planning to return to my home in Canada, planning the variety of ways through which I could reconstruct my life as a "de-institutionalized" academic.

\section{The Paradox of the Institution}

In the soul-searching that followed my return to Canada, I soon began to realize that complete "de-institutionalization" was probably impossible. One of the paradoxes of my "life on the outside" of academia results from my continued dependence upon a number of institutions to legitimate what I write, even in the instance of this ACT special issue, for which the "institution" of the MayDay Group $^{1}$ sanctions my speech as a guest editor. The institution, as Bourdieu tells us, permits certain individuals to speak when they are so authorized, and authorization requires being recognized, by others, to speak because an individual is "able to speak in a way that others will regard as acceptable in the circumstances ... the very mechanisms through which those who speak attest to the authority of the institution which endows them with the power to speak" (Bourdieu 1991, 9, italics in original). Thus my years as an undergraduate, then graduate student, and as an instructor at the University of Toronto (both before and after my time at the University of Wisconsin-Madison), my contractual affiliation with Boston University, my work with the MayDay Group, and my peer-reviewed publications all serve to authorize my utterances on the topic of institutional injustice. In listing for the reader these credentials that authorize my right to speak, I knowingly

Bradley, Deborah. 2017. Interrogating the grammars of institutions and injustice. Action, Criticism, and Theory for Music Education 16 (3): 1-14. doi:10.22176/act16.3.1 
grant the institution the power of authorization. I may have left the institution, but the institution has not left me. In Bourdieusian terms, these institutions helped me to develop personal capital with respect to academic thinking and writing. Even though I initially attempted to distance myself from the institution, my actions "on the outside" remain "compatible with still belonging to it" (Bourdieu 1991, 196).

This paradox of institutional life has long been a source of frustration and fascination for me, as I imagine it may be for many readers, and this paradox represents one of the purposes for this ACT special issue on "institutional injustice." Drawing from the epigraph that began this editorial essay, as academics we may know institutions "to death" and somehow remain ignorant of them. How is it that institutions of education, at all levels, can declare that their purpose is to educate while they, with increasing intensity, obfuscate what it means to educate through the enactment of neoliberal policies (Giroux 2010)? Higher education, in particular, has become "an outpost of business culture simply there to do the bidding of corporate power" (Giroux 2010, 7), mimicing inequalities and hierarchies of power, undermining civic education, public values, and confusing education with training (5). As Giroux argues, we are experiencing an educational crisis in which the institutions of public and higher education have been conscripted into a war on democratic values (15). Neoliberal ideologies are reshaping higher education more generally through widespread ideologies of curricular standardization, top-down management, proscriptions on behavior, and invasive systems of accountability (Jones Jr. and Calafell 2012, 958). The quest for profit has infiltrated higher education, making higher education resemble a corporate/competitive model (964).

A central tenet of institutional theory is that organizations in a field come to exhibit similar traits over time, what has been termed a "push towards homogenization driven by a quest for legitimacy and resources" (Barman and MacIndoe 2012, 71). The business model of higher education requires this push towards homogenization, forcing ever more sites of higher education into the model of the so-called corporate university. "Although universities were not key in creating neoliberal policies and ideologies, they have directly and indirectly endorsed such policies" (Jones Jr. and Calafell 2012, 964). Thus higher education is complicit in producing and legitimating the current neoliberal rationality, spawning rapacious greed, grotesque levels of inequality, the devaluation of viable notions of the

Bradley, Deborah. 2017. Interrogating the grammars of institutions and injustice. Action, Criticism, and Theory for Music Education 16 (3): 1-14. doi:10.22176/act16.3.1 
public good, and widespread human suffering (Giroux 2010, 15). At the same time, these results are masked through the adoption of "corporate multiculturalism" (Gilroy 2000) which frames diversity as entertaining and unproblematic (Jones Jr. and Calafell 2012).

I think here of the annual "diversity days" held on so many college campuses. Their intent is to promote diversity and problematize strategies for increasing diversity among both the student population and the professoriate, yet so far results have been not simply underwhelming, institutions are losing ground with respect to diversity. Recent research indicates that despite Affirmative Action programs, Blacks and Hispanics in the U.S. are more underrepresented in higher education than they were 35 years ago (Ashkenas, Park, and Pearce 2017). It is easy to say this is the result of systemic or institutional racism, and while such statements are not "wrong," they are somewhat incomplete. "Despite calling attention to the institutional or structural processes that reproduce racial inequality, they [race scholars] still insist on labeling these processes as 'racism' of one sort or another" (Ditomaso, Parks-Yancy, and Post 2003, 190) rather than focusing on the legally supported institutional issues and behaviors that contribute to these dismal results. Labeling something as "racism" without further analysis may serve to obscure the specific policies and behaviors that reinscribe racism as an outcome of institutional behavior. As Ditomaso et al. argue,

there has been insufficient attention given to processes of favoritism or inclusion that help Whites (instead of harming Blacks and other nonwhites). While some may argue that discrimination and favoritism are different sides of the same coin, discrimination is illegal, whereas favoritism is not (Ditomaso, ParksYancy, and Post 2003, 190)

\section{The Grammar of Institutional Injustice}

The argument above by Ditomaso et al., while avoiding the term White privilege, speaks clearly to the advantage that privilege provides to White people. Although this particular issue of ACT goes beyond questions of racial injustice, issues of privilege seem to provide at some level a subtext for all of the articles in the issue. How do institutions support systems of favoritism that advantage some and disadvantage others? As Eduardo Bonilla-Silva (2011) might ask, what is the "grammar" of institutions that actually prevents the very work towards equity that their mission statements promote? "[R]acial grammar helps accomplish this

Bradley, Deborah. 2017. Interrogating the grammars of institutions and injustice. Action, Criticism, and Theory for Music Education 16 (3): 1-14. doi:10.22176/act16.3.1 
task by shaping in significant ways how we see or don't see race in social phenomena, how we frame matters as racial or not race-related, and even how we feel about race matters" (Bonilla-Silva 2011, 174). As Bonilla-Silva further describes, his use of grammar moves beyond the linguistic connotations of the term; racial grammar influences vision, emotion, and our sense of aesthetics in addition to the way we talk about and frame racial matters (188).

While not all of the articles in this issue of ACT deal with the grammar of race, it bears note that the "inspiration" for this issue emerged from an incident in which race played a central role. On April 26, 2016, then President of NAfME, ${ }^{2}$ Michael Butera, attended a meeting organized by the National Endowment for the Arts to address concerns for diversity in the arts. Outrage erupted when Butera responded to a question about how NAfME might better diversify its Board of Directors. Mr. Butera allegedly stated that the NAfME board was elected, and therefore he could not unilaterally diversify it, followed at some point by a comment suggesting that "Blacks and Latinos don't have the keyboard skills needed for this" (Cooper 2016). Mr. Butera has denied the accuracy of accounts of the incident and offered the following further explanation:

"I also mentioned that the field of music educators, much like the general population of educators, is skewed toward [W]hite individuals," he wrote. "We have had ongoing and rich discussions in our association community about how best to address this issue, but have not yet been able to actualize a solution. This is not for lack of trying, but simply because of the enormous complexity of the issue." (Cooper 2016)

The unfortunate incident, which led to Mr. Butera's resignation two weeks later (on May 9, 2016), may now be but a faded memory of the past 18 months; however, his statements highlight the grammar of institutional injustice within music education. What is it about the structure of NAfME and other organizations that favors certain types of musicians and educators, enabling some to rise to leadership roles while lamenting the continuing lack of diversity in the organization?

Because Mr. Butera's remarks were quickly labeled as racist, his resultant resignation may have forestalled further investigation into the nature of the institutional racism the remarks identified. As music educators, we cannot overlook the seemingly omnipresent everyday racism, the racial grammar within institutional structures and curricula that continue to discourage and disadvantage students of colour (Koza 2008, Gustafson 2008), nor does acknowledg-

Bradley, Deborah. 2017. Interrogating the grammars of institutions and injustice. Action, Criticism, and Theory for Music Education 16 (3): 1-14. doi:10.22176/act16.3.1 
ing the enormous complexity of the issues absolve us from complicity with the perpetuation of that racial grammar.

Institutional racism has been perhaps most notably visible in recent weeks in the actions of the U.S. president, Donald Trump, who on October 4, 2017, threw out rolls of paper towels to the survivors of hurricane Maria in Puerto Rico. That action will forever stand as a reminder of the normalization of racism, symbolized by an action that visibly confirmed the second-class citizenship of Puerto Ricans within U.S. society (Maqbool 2017). 3 As Bourdieu wrote, "the institution, understood as that which is already instituted, already made explicit, creates at one and the same time an effect of public care and lawfulness and an effect of closure and dispossession" (Bourdieu 1991, 173). The rolls of paper towels thrown to hurricane survivors physically illustrated all of Bourdieu's points: as a display of public care and lawfulness (represented in the actions of the nation's leader), an effect of closure (the president has fixed your problem), and dispossession (if Puerto Ricans were "real" citizens of the U.S., we might do more than throw you a paper towel or two4).

One could apply Bourdieu's argument as easily to Affirmative Action programs among institutions of higher education, given their general failure to increase diversity among faculty and students. The proposal of Affirmative Action legislation served as a governmental declaration of concern for women and minorities who were disadvantaged in the hiring market and thus offered a legal remedy. Passing such legislation into law served as closure on the issue (unfair hiring practices were illegal); dispossession occurred when the legislation appeared to help some of its intended beneficiaries; however, the colorblind nature of the legislation's original language in reality benefitted White people more than its supposed intended beneficiaries (Ashkenas, Park, and Pearce 2017, Ciocchetti and Holcomb 2010, Ladson-Billings 2010, Ladson-Billings and Tate 2009, Zimmerman 2017).

Even before hurricanes Harvey and Irma devastated the U.S. mainland, or hurricane Maria wreaked havoc on the U.S. territories of the Virgin Islands and Puerto Rico, examples of everyday institutional injustice in the form of racism filled the news, coming to a head in Charlottesville, VA, on August 12, 2017, when the institutionally/constitutionally guaranteed right to free speech protected White supremacists' right to gather publicly, despite the various groups' public calls for genocide, ethnic cleansing, and violence. 5 Neo-Nazis and other White

Bradley, Deborah. 2017. Interrogating the grammars of institutions and injustice. Action, Criticism, and Theory for Music Education 16 (3): 1-14. doi:10.22176/act16.3.1 
supremacists marched through the streets of Charlottesville, carrying torches and chanting, "Jews will not replace us!" After a car driven by one of the White supremacists deliberately sped into a crowd of counter protestors, killing Heather Heyer, the U.S. president attributed the violence to "many sides," and thus failed to condemn the White supremacist groups who initiated that violence (Cillizza 2017). In both Puerto Rico and Charlottesville, the institution of government sanctioned Donald Trump's actions and statements, and even though individuals criticized his remarks and actions-just as the easy argument blamed the violence in Charlottesville on particular individuals--institutions authorized the gathering of White supremacists, the actions of the president, FEMA's ${ }^{6}$ questionable response time in Puerto Rico (Greenwood 2017), and provided a platform for Michael Butera.

It is important here to understand that White supremacy operates on multiple levels. It is not defined simply as the racist words and actions espoused by Neo-Nazis or the KKK; it encompasses a much broader and deeper problem. White supremacy represents the system that awards systemic privileges to those who have been racialized as "white." It is an ideological mechanism responsible for the reproduction of racial privilege in society and the perpetuation of systemic white privilege (Bonilla-Silva 2003, 9). White supremacy lies at the foundation of the racial grammar of institutions, including that of the U.S. government (Ladson-Billings 2010, Ladson-Billings and Tate 2009), and defines the "techniques and processes of reasoning about social facts" (Bonilla-Silva 2008, 17).

Both Mr. Butera's statements and the words and actions of the current U.S. president suggest that institutions, despite mission statements, legislation, and constitutions to empower their actions otherwise, 7 harbour and promote injustice. Butera's infamous statement in April 2016 conveyed the sad reality of the grammar of institutional racism that obstructs Blacks and Latino/as and others from attaining positions of authority within the NAfME ranks. The U.S. president's words and actions simultaneously conveyed and normalized the grammar of racism within the U.S. government. As Bonilla-Silva explains, these events represent "a grammar to normalize the standards of white supremacy as the standards for all sorts of everyday transactions rendering domination almost invisible" (Bonilla-Silva 2011, 174). Located within the deep structures of institutions, such racial grammar appears both normal and natural to people in this culture (Ladson-Billings 2010).

Bradley, Deborah. 2017. Interrogating the grammars of institutions and injustice. Action, Criticism, and Theory for Music Education 16 (3): 1-14. doi:10.22176/act16.3.1 
In Language and Symbolic Power, Bourdieu (1991) illuminates how institutions allow for and may actually encourage injustice. In order to capture the nuance of his argument as it relates to the above paragraphs, I quote at length:

This means that, to gain a complete understanding of the political discourses that are on offer in the market at a given moment and which, when considered together, define the universe of what can be said and thought politically, as opposed to what is rejected as unsayable and unthinkable, we would have to analyse the entire process of production of the professionals of ideological production, starting with the way they are marked out, according to the frequently implicit definition of the desired competence, which designates them for these functions, then considering the general or specific education which prepares them to assume these functions, and finally examining the action of continuous normalization imposed on them, with their own complicity... (176)

As Nau (2005) asks, "what influence do institutions have on the behaviour of individuals and vice versa?" (129). Max Weber asserted that institutions serve "as a representation of the 'rules of the game' upon which human behaviour bases itself" (Nau 2005, 130); with this understanding it thus becomes critical to interrogate how institutions determine the "rules of the game" that affect music educators, both as individuals and as actors within institutional settings. How does the grammar of the institution affect the way the rules are created, what rules are created, how those rules are enforced, and who benefits from those rules? As Bonilla-Silva argues, however, no "grammar completely rules a field at any point in time," and thus "rules are transacted and negotiated so that ideological rule and order are always in tension and conflict" (Bonilla-Silva 2011, 174). A critical interrogation of the grammar of institutions can lead individual actors within those institutions to begin the work necessary to change the rules of the game. 'Through 'rebellion' from 'speakers,' the grammar may change or collapse altogether" (175). Thus studying the various ways that institutions may promote injustice, knowingly or otherwise, represents an important first step towards changing their grammars.

\section{In the Issue}

This special issue of Action, Criticism, and Theory attempts to dissect a number of the grammars of institutional or structural injustices. My purpose in this section is not to provide a detailed overview of the various essays but rather to contextualize them within the grammars of institutional injustices. Each article

Bradley, Deborah. 2017. Interrogating the grammars of institutions and injustice. Action, Criticism, and Theory for Music Education 16 (3): 1-14. doi:10.22176/act16.3.1 
offers its own perspective that contributes to a more broadly understood picture of the multiple injustices found within institutions. Although only one essay attempts an analysis of a specific institution, all the essays focus in some way on the grammar of a particular structural injustice located in various academic and governmental institutions.

Juliet Hess's examination of "race-related silences and the importance of using direct language to identify structural and systemic racism" is reminiscent of my own early forays into the exploration of language use in music education and multiculturalism (Bradley 2007, 2006). That Hess is writing along these lines a decade later speaks volumes about the slow pace of change in institutional behavior. Language continues to serve as an oppressive tool that silences discussions, rather than providing the platform for problem-solving dialogue. Drawing upon a Critical Race Theory (CRT) framework, Hess calls for music educators to move away from "terminal naivety" (Vaugeois 2013) that prevents not only the recognition of whiteness and Eurocentricity present in institutions of music, but also prevents us from understanding "the ways in which masking systems serve to perpetuate these facets of institutions." Her arguments find commonality with Bonilla-Silva's (2011) concerns about the grammar of structural racism; her analysis of how the language we use, as well as the language we avoid, sheds light on how individuals and institutions perpetuate a lack of awareness (terminal naivety) of racial injustices both in music education as a discipline and the institutions within which we work.

Nasim Niknafs offers a personal and poignant account of how institutional grammar related to terror and terrorism affects her as an Iranian academic now living in Canada. Drawing upon Homi Bhabha's concept of enunciation, Niknafs articulates in rich language how othered faculty experience "systemic inequity in their academic lives and misperceptions about their music education." Her narrative explores systemic inequity on a number of fronts: from government edicts to institutional appraisals of "other people's" educations to a pointed critique of the assessment of tenure portfolios that may disadvantage scholars affected by recent U.S. travel rulings and by long-standing restrictive visa requirements.

Niknafs' narrative may be read in this issue as providing a segue to the article by Heidi Westerlund and Sidsel Karlsen, in which they raise important issues for scholars involved in research leading to transnational knowledge

Bradley, Deborah. 2017. Interrogating the grammars of institutions and injustice. Action, Criticism, and Theory for Music Education 16 (3): 1-14. doi:10.22176/act16.3.1 
production. They critique the ideological context through which notions of diversity are produced; in doing so they ask readers to consider what it means to be reflexive in our thinking when situations of collaborative knowledge production bring into contact representatives of cultures with different ways of thinking about and coping with the world. Using a term borrowed from media studies, they call for a move beyond "ocularcentrism of diversity" to "develop a more heterogenous, ethically and politically conscious kaleidoscopic reflexivity in music teacher education." The questions they raise throughout their discussions speak to the current grammars of multicultural thinking and research, and simultaneously offer music educators a new language and perspective for collaborative and transcultural research projects.

Adam Patrick Bell turns to the sport of wheelchair basketball and the perspectives of paralympian Patrick Anderson to probe issues of disability within music education. As a discipline, music education commonly relies on the grammar of a medical model of disability that imagines music making as the purview of an "idealized body." As with other articles in this issue, the concept of silencing plays out significantly through the very grammars of disability used within music education-through language that attempts to "fix" meanings of ability and disability, rather than viewing disability as a continuum along which the condition of health varies based upon one's circumstances. And while the social model of disability may seem to provide a viable alternative for thinking about disability, Bell pushes readers to think about when and how that perspective may be just as disabling as the medical model's focus on deficit.

The final article in this issue of ACT comes from Lauri Väkevä, Heidi Westerlund, and Leena Ilmola-Sheppard, who conducted a systems analysis of the Finnish extracurricular arts education system to find ways in which injustices embedded within the system may be not merely disrupted, but set on a direction for change that can develop resilience against future institutional grammars of injustice. Their perspectives on how to promote a culture of institutional change provide a fresh perspective on the subject. Their research provides ways of thinking about how music education might "create resilience and better serve the whole population in these times of rapid societal change."

Bradley, Deborah. 2017. Interrogating the grammars of institutions and injustice. Action, Criticism, and Theory for Music Education 16 (3): 1-14. doi:10.22176/act16.3.1 


\section{In Closing}

While it is understandable that readers will select articles from this issue that are the most relevant to their own trajectories of research and writing, I hope that many will choose to look at this issue in its entirety for the breadth of perspectives offered herein. Scholarship representing critical race theory, postcolonial studies, disability studies, new theorizing emerging from research in multicultural education, and systems analysis research targeting ways to build resiliance toward greater social justice in institutional settings, combine to not only critique institutions and injustice but also to offer positive and practical suggestions for change. I hope you enjoy reading this issue as much as I have enjoyed working with the authors on this special issue of Action, Criticism, and Theory as its Guest Editor. The collective perspectives represented in this issue may help us all understand a bit better the institutions we may think we "know to death."

\section{About the Author}

Deborah Bradley received a Ph.D. in Sociology \& Equity Studies in Education from OISE/University of Toronto. She was Assistant Professor in the Department of Curriculum and Instruction at the University of Wisconsin-Madison from 2006- 2010, and taught at the University of Toronto from 1997-2005 and 20102014. She retired from UW-Madison in 2010 and the University of Toronto in 2014. Her publications on antiracism education include articles in ACT, Philosophy of Music Education Review, Journal of Aesthetic Education, Music Education Research, Theory into Practice, and chapters in several Oxford University Press handbooks: Philosophy of Music Education (2012), Handbook of Music Education and Social Justice (2015), the Handbook of Choral Pedagogy (2016), and College Music Curricula for a New Century (2017). Deb has served as Editor in Chief for MayDay Group publications since 2015.

\section{References}

Ashkenas, Jeremy, Haeyoun Park, and Adam Pearce. 2017. Even with affirmative action, Blacks and Hispanics are more underrepresented at top colleges than 35 years ago. New York Times, Aug 24: 1-18. https://www.nytimes.com/ interactive/2017/o8/24/us/affirmativeaction.html?emc=edit_ta_20170824 \&amp;nl=top-stories\&amp;nlid=48543449\&amp;ref=headline\&amp; r=o.

Barman, Emily, and Heather MacIndoe. 2012. Institutional pressures and organizational capacity: The case of outcome measurement. Sociological Forum 27 (1): 70-93. doi: 10.1111/j.1573-7861.2011.01302.x.

Bradley, Deborah. 2017. Interrogating the grammars of institutions and injustice. Action, Criticism, and Theory for Music Education 16 (3): 1-14. doi:10.22176/act16.3.1 
Bonilla-Silva, Eduardo. 2003. Racism without racists: Color-blind racism and the persistence of racial inequality in the United States. Lanham: Rowman \& Littlefield.

Bonilla-Silva, Eduardo. 2008. Toward a definition of white logic and white methods. In White logic, White methods, edited by Tukufu Zuberi and Eduardo Bonilla-Silva, 3-27. Lanham, MD: Rowman \& Littlefield Publishing Group.

Bonilla-Silva, Eduardo. 2011. The invisible weight of whiteness: The racial grammar of everyday life in contemporary America. Ethnic and Racial Studies 4: 173-94. doi: 10.1080/01419870.2011.613997.

Bourdieu, Pierre. 1991. Language and symbolic power. Edited by John B. Thompson. Cambridge, Mass.: Harvard University Press.

Bradley, Deborah. 2006. Music education, multiculturalism, and anti-racism can we talk? Action, Criticism, and Theory for Music Education 5 (2).

Bradley, Deborah. 2007. The sounds of silence: Talking race in music education. Action, Criticism, and Theory for Music Education 6 (4): 132-62.

Cillizza, Chris. 2017. Donald Trump's incredibly unpresidential statement on Charlottesville. [Commentary]. CNN.com, Last Modified Aug 13.

Ciocchetti, Corey A, and John Holcomb. 2010. The frontier of affirmative action: Employment preferences and diversity in the private workplace. University of Pennsylvania Journal of Business Law 12 (2): 283-349.

Cooper, Michael. 2016. Music education group's leader departs after remarks on diversity. The New York Times, May 12, 2016, 1-3. https://www.nytimes. com/2016/05/13/arts/music/music-education-groups-leader-departs-afterremarks-on-diversity.html

Ditomaso, Nancy, Rochelle Parks-Yancy, and Corinne Post. 2003. White views of civil rights: Color blindness and equal opportunity. In White out: The continuing significance of racism, edited by Ashley W. Doane and E. BonillaSilva, 189-98. New York \& London: Routledge.

Gilroy, Paul. 2000. Against race. Cambridge, MA: Belknapp Press of Harvard University Press. Original edition, 2000. Reprint, 2001, 4th printing.

Giroux, Henry A. 2010. Public values, higher education and the scourge of neoliberalism: Politics at the limist of the social. Culture Machine: 1-18.

Bradley, Deborah. 2017. Interrogating the grammars of institutions and injustice. Action, Criticism, and Theory for Music Education 16 (3): 1-14. doi:10.22176/act16.3.1 
Greenwood, Max. 2017. Senate Dems demand quicker FEMA response in Puerto Rico | TheHill. [Article], Last Modified Oct 27. http://thehill.com/homenews /senate/357550-senate-dems-write-fema-demanding-quicker-response-inpuerto-rico.

Gustafson, Ruth. 2008. Drifters and the dancing mad: The public school music curriculum and the fabrication of boundaries for participation. Curriculum Inquiry 38 (3):267-97. doi: 10.1111/j.1467-873X.2008.00409.x.

Jones Jr., Richard G, and Bernadette Marie Calafell. 2012. Contesting neoliberalism through critical pedagogy, intersectional reflexivity, and personal narrative: Queer tales of academia. Journal of Homosexuality 59 (7): 957-81. doi: 10.1080/00918369.2012.699835.

Koza, Julia E. 2008. Listening for Whiteness: Hearing racial politics in undergraduate school music. Philosophy of Music Education Review 16 (2): $145-55$.

Ladson-Billings, Gloria. 2010. Just what is critical race theory and what's it doing in a nice field like education? International Journal of Qualitative Studies in Education 11 (1): 7-24. doi: 10.1080/095183998236863.

Ladson-Billings, Gloria, and William F. Tate. 2009. Toward a critical race theory of education. In The critical pedagogy reader, 167-82. New York: Routledge.

Maqbool, Aleem. 2017. Puerto Rico: Trump paper towel-throwing "abominable." Oct 04, 1-10, U.S. and Canada. http://www.bbc.com/news/world-uscanada-41504165.

Nau, Heino Heinrich. 2005. Institutional evolutionary and cultural aspects in Max Weber's social economics. Papers in Political Economy 49 (2): 127-42.

Vaugeois, Lise. 2013. Colonization and the institutionalization of hierarchies of the human through music education: Studies in the education of feeling. PhD dissertation, Faculty of Music, University of Toronto.

Zimmerman, Jonathan. 2017. Who's benefiting from affirmative action? White men. The Washington Post, Aug 11, 1-3. https://www.washingtonpost.com/ opinions/who-benefits-from-affirmative-action-white-men/2017/o8/11/4b5 6907e-7eab-11e7-a669-b400c5c7e1cc_story.html?utm_term=.64c9b83c487e

Bradley, Deborah. 2017. Interrogating the grammars of institutions and injustice. Action, Criticism, and Theory for Music Education 16 (3): 1-14. doi:10.22176/act16.3.1 


\section{Notes}

${ }^{1}$ The MayDay Group first came into being as an ad-hoc group, an informal collective of thinkers who shared certain principals and ideals related to music and music education. Over time, however, as the group grew in membership, it required some form of governance. With the addition of the academic, peerreviewed journals ACT and TOPICS, and as a result of the group's stated Action Ideals which serve to provide a statement of common purpose, MayDay group developed into what could be considered an institution, although officially the group identifies as an "international think tank."

2 NAfME stands for National Association for Music Education.

3 It bears mention the photo op for the towel throwing actually occurred in Guaynabo, a wealthy area of Puerto Rico.

4 It bears mentioning that the paper towel throwing occurred during a press briefing, and does not represent the sum of efforts by FEMA and other agencies in Puerto Rico following from the hurricane; I use the image here as symbolic of the US government's institutional racism.

5 https://itsgoingdown.org/need-know-nazi-rally-charlottesville-va/

6 Federal Emergency Management Association

7 For example, the NAfME website states: "Since 1907, NAfME has worked to ensure that every student has access to a well-balanced, comprehensive, and high-quality program of music instruction taught by qualified teachers" (https://nafme.org/about/).

Bradley, Deborah. 2017. Interrogating the grammars of institutions and injustice. Action, Criticism, and Theory for Music Education 16 (3): 1-14. doi:10.22176/act16.3.1 